\title{
Modeling and Analysis of Amplitude-Frequency Characteristics of Torsional Vibration for Automotive Powertrain
}

\author{
Jinli Xu, Jiwei Zhu (D), and Feifan Xia \\ School of Mechanical and Electronic Engineering, Wuhan University of Technology, 122 Luoshi Road, Hongshan District, \\ Wuhan 430070, Hubei, China \\ Correspondence should be addressed to Jiwei Zhu; edwinzjw@163.com
}

Received 3 December 2019; Revised 21 July 2020; Accepted 31 July 2020; Published 29 August 2020

Academic Editor: F. Viadero

Copyright ( 92020 Jinli Xu et al. This is an open access article distributed under the Creative Commons Attribution License, which permits unrestricted use, distribution, and reproduction in any medium, provided the original work is properly cited.

In the present paper, the amplitude-frequency characteristics of torsional vibration are discussed theoretically and experimentally for automotive powertrain. A bending-torsional-lateral-rocking coupled dynamic model with time-dependent mesh stiffness, backlash, transmission error etc. is proposed by the lumped-mass method to analysis the amplitude-frequency characteristic of torsional vibration for practical purposes, and equations of motive are derived. The Runge-Kutta method is employed to conduct a sweep frequency response analysis numerically. Furthermore, a torsional experiment is performed and validates the feasibility of the theoretical model. As a result, some torsional characteristics of automotive powertrain are obtained. The first three-order nature torsional frequencies are predicted. Torsional behaviors only affect the vibration characteristics of a complete vehicle at low-speed condition and will be reinforced expectedly while increasing torque fluctuation. Gear mesh excitations have little effects on torsional responses for such components located before mesh point but a lot for ones behind it. In particular, it is noted that the torsional system has a stiffness-softening characteristic with respect to torque fluctuation.

\section{Introduction}

The front-engine, rear-wheel drive layout (FR) vehicle has a complicated powertrain consisting of engine, clutch, transmission, drive shaft, rear axle, and tire, as shown in Figure 1, which indicates that more dynamic behaviors occur. In a typical dynamic operating condition, the fluctuation of engine output torque, $\mathrm{U}$-joint dynamic characteristics will induce torsional vibration of the whole powertrain. Internal excitations originating from inherent characteristics of hypoid gear set also are responsible for the transverse-torsional-rocking coupled vibration of rear axle. These vibrations are eventually transmitted to the vehicle body through intermediate support and suspension to act as the main aspects of excitations causing vibration and noise for the complete vehicle. In order to improve the dynamic performances for vehicle, a number of research studies had been performed.

Vesali et al. [1] obtained the relationship between input and output angular speed for different $\mathrm{U}$-joint with variations in structure. $\mathrm{Lu}$ et al. [2] proposed a dynamic model with clearance by the lumped-mass method to discuss dynamics of a cross shaft type universal joint and analyze the effects of clearance on output speed and dynamic torque response. $\mathrm{Wu}$ et al. [3] optimized the phase differences between adjacent $\mathrm{U}$-joints, which reduced the torsional vibration of transmission shaft. A classical model was proposed by Porter [4] in which the transmission system containing a $\mathrm{U}$-joint was modeled as a torsional system with one degree-of-freedom. Asokanthan and Wang [5] introduced a torsional model with two degree-of-freedom to investigate stability and bifurcation performances by using the maximum Lyapunov exponent method based on Porter's model. Farshidianfar et al. [6] developed a lumped-mass model for a driveline forced by torsional excitation to analyze the formation mechanism of noise. Friction was considered in Abd Elmaksoud's paper [7], whose investigation indicated that the friction moment is a main aspect of excitationinducing torsional vibration for the automobile driveline. Juang et al. [8] discussed effects of the sliding-tube-type 


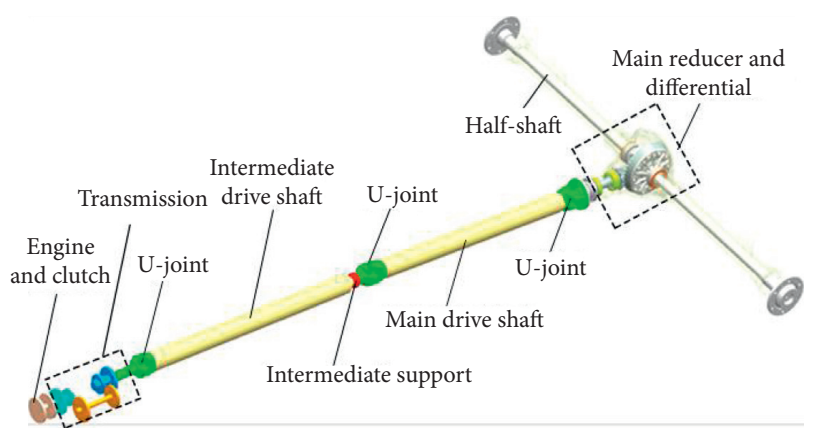

FIGURE 1: Schematic of the automotive powertrain system discussed in this paper.

driveshaft on a complete vehicle by experimental and finite element method. They reached a conclusion that fluctuation of nonlinear contact force in sliding mechanism accounts for the complete vehicle vibration. Coutinho and Tamagna [9] analyzed the bending natural frequency of half-shaft to prevent from resonance under power excitation. The effects of intermediate support on complete vehicle vibration are discussed in Yiting Kang's work [10]. Xu et al. [11] and Zhang et al. [12] analyzed dynamics of transmission shaftrear driving axle based on ADAMS and experimental demonstration, and the coupling effects between transmission shaft and rear axle were discussed. Xu et al. [13] and $\mathrm{Xu}$ et al. [14] developed several different dynamic models considering coupling interaction between automobile transmission shaft and main reducer. In their studies, effects of bearing stiffness, backlash, intermediate support, etc. on the system were discussed numerically. It is noted that the key of analytical solution for the main reducer is the development of the dynamic model of hypoid gear, with timevarying meshing stiffness, damping, clearance, bear, and other line or nonlinear factors, which inherits the research studies on spur and helical gear pair conduct by Kahraman and Singh [15-17], Cai and Hayashi [18], and Velex et al. [19-21], and remarkable achievements can be found within documents of Lim's team [22-26] and other researchers.
As introduced in preceding section, a few investigations treating engine, clutch, transmission, transmission shaft, and rear axle as a whole system were conducted mathematically. Although many models have been introduced in the literature, very few considered the influence of transverse and rocking vibration on torsional performances theoretically for discussing torsional characteristics of powertrain. In the present paper, the amplitude-frequency characteristics of torsional vibration for automotive powertrain are analyzed theoretically and experimentally considering the interactions between powertrain and the main reducer gear system.

As for the layout of the present paper, it mainly contains five sections besides introduction. In the second section, a lumped-parameter dynamic model with 29 degree-of-freedom is proposed considering the transverse, torsional, and rocking vibration, and equations of motion are derived. In the third section, the introduced model is adopted to discuss the amplitude-frequency characteristics of torsional vibration for the coupling system by sweep frequency response analysis numerically. In the fourth part, an experiment is performed to validate the feasibility of the considered model and analyze the effect of torque fluctuation on the amplitude-frequency characteristics of torsional vibration. As the final part, a conclusion is offered.

\section{Dynamic Modeling of Powertrain}

As shown in Figure 1, the powertrain discussed in this paper consists of engine, transmission, drive shaft system, and rear axle. Considering the complexity of the system, a series of simplifying processes are adopted to establish the dynamic model of the system by using lumped-parameter method. Thereby, a generalized model with twenty-nine degree-offreedom (29DOF) is proposed as shown in Figure 2, in which U-joint dynamic actions, intermediate support stiffness, time-varying mesh stiffness, gear backlash, static transmission error, and other factors are considered.

The generalized coordinate vector of the dynamic model is given by

$$
\{S\}=\left\{\begin{array}{c}
\theta_{1}, \theta_{2}, \theta_{3}, \theta_{4}, \theta_{5}, \theta_{6}, \theta_{7}, \theta_{8}, \theta_{9}, \theta_{10}, \theta_{11}, \theta_{12}, \theta_{13}, \theta_{14}, \theta_{15}, \theta_{16}, \theta_{17}, \\
\theta_{p y}, \theta_{p z}, \theta_{g x}, \theta_{g z}, y_{m}, z_{m}, x_{p}, y_{p}, z_{p}, x_{g}, y_{g}, z_{g}
\end{array}\right\}^{\mathrm{T}},
$$

where $\theta_{i}(i=1-5)$ represents the torsional displacement of the equivalent element as their coordinates; $y_{m}$ and $z_{m}$ are the translations of the intermediate support along the axes $y$ and $z ; x_{p x}, x_{p y}$, and $x_{p z}$ are the translations of the pinion along the axes $x, y$, and $z ; x_{g x}, x_{g y}$, and $x_{g z}$ are the translations of the gear along the axes $x, y$, and $z ; \theta_{p x}$ is the torsional displacement of the pinion around the $x$ axis; $\theta_{p y}$ and $\theta_{p z}$ are the rocking displacements of the pinion around the $y$ and $z$ axes; and $\theta_{g x}$ and $\theta_{g z}$ are the rocking displacements of the gear around the $x$ and $z$ axes, respectively.
The equivalent mass and moment of inertia are denoted by $m_{i}$ and $J_{i}$.

2.1. Engine. In order to satisfy limitations of experimental bench, parameters of engine are replaced by ones of input motor, which is processed as two equivalent moments of inertia corresponding to the equivalent moments of inertia of the motor, flywheel, and clutch.

Output torque of engine, as a main external excitation of the system, is written as in Fourier series form: 


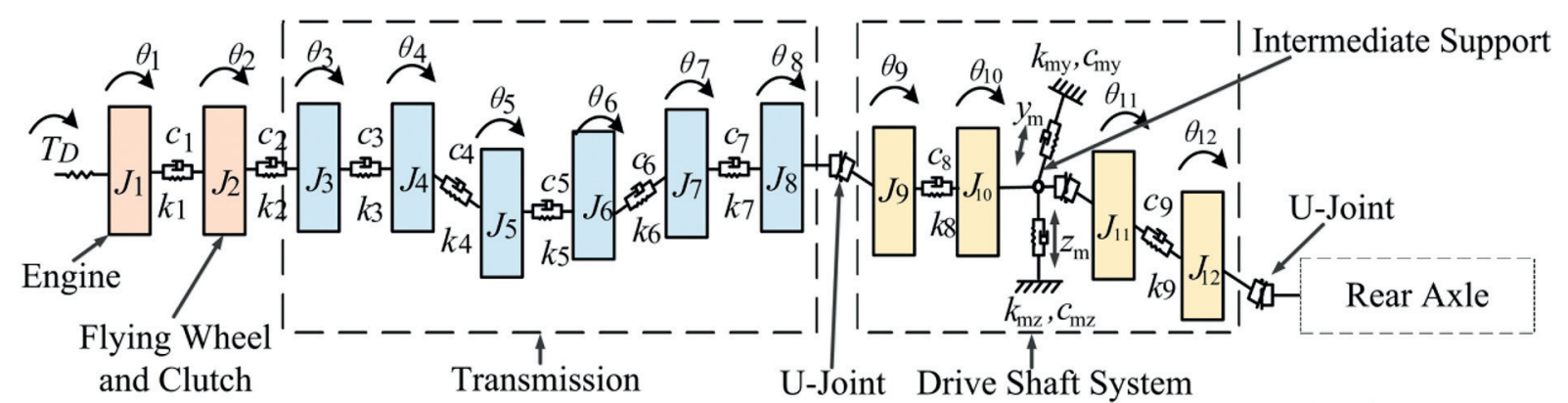

(a)
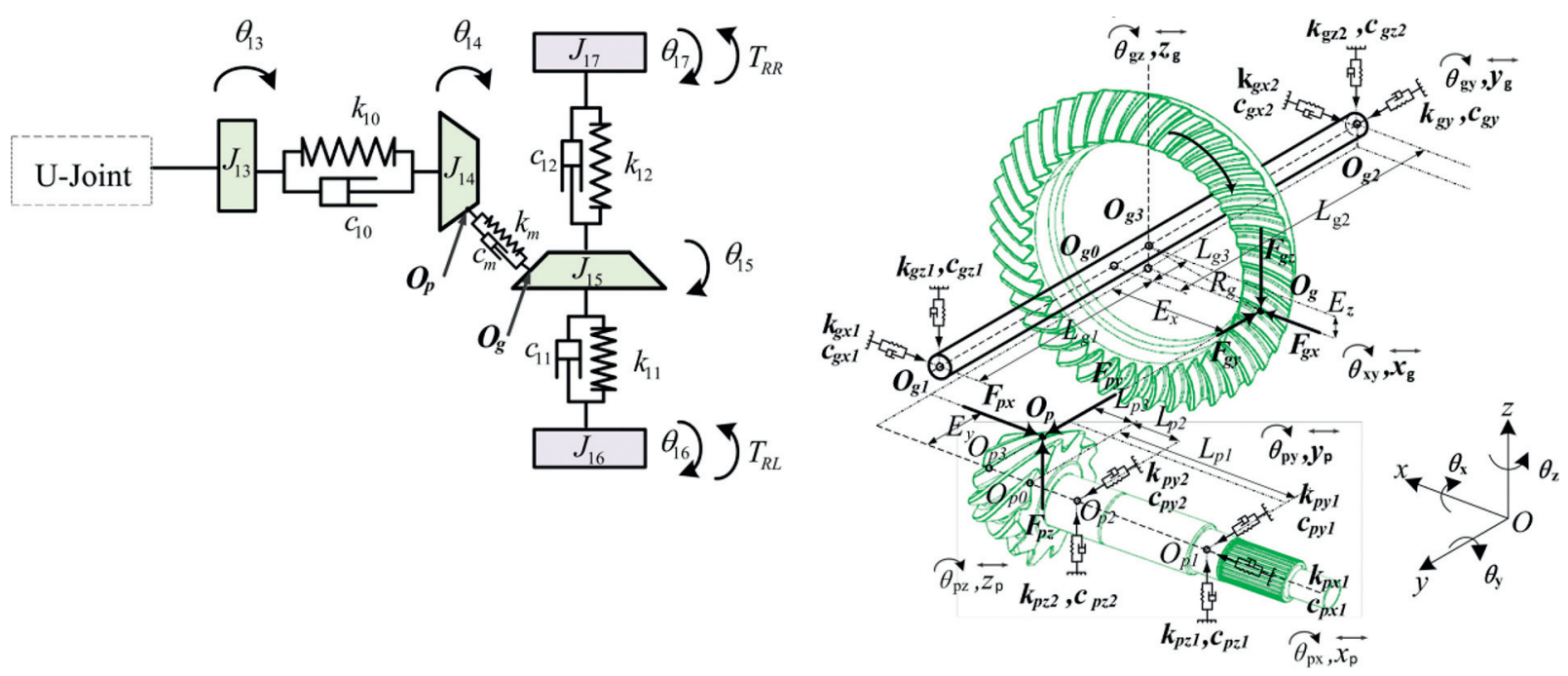

(b)

(c)

FIgURe 2: The dynamic model of the powertrain shown in Figure 1: (a) dynamic model of powertrain without rear axle; (b) torsional model of rear axle; (c) dynamic model of the main reducer in rear axle.

$$
T_{D}=T_{m}+\sum_{i=1}^{N} T_{d i} \cos \left(i \omega_{f} t+\varphi_{i}\right)
$$

where $T_{m}$ is mean output torque; $T_{d i}$ is the amplitude of $i$ th harmonic term; $\omega_{f}$ is output speed of engine; and $\varphi_{i}$ is phase angel of $i$ th harmonic term.

Based on previous research [14], only mean component and the second-order harmonic term are considered here:

$$
T_{D}=T_{m}+T_{d 2} \cos \left(2 \omega_{f} t+\varphi_{2}\right) .
$$

2.2. Transmission. The transmission is simplified as a chained system with six equivalent moments of inertia, and $i_{1}$ is introduced to describe the drive ratio of transmission. Furthermore, gears are assumed as rigid, and gear mesh characteristics, frictions, etc. are neglected. Without loss of generality, the case of $i_{1}=1.350$ is employed as an example in the present work.

In order to simplify a multimesh gear train into a chained system, a shaft should be chosen as the main body firstly as illustrated in Figure 3, in which $J_{i}(i=1-4)$ and $J_{i}^{\prime}(i=3-4)$ are equivalent moments of inertia and $K_{i}$ $(i=1-4)$ and $K_{i}^{\prime}(i=3-4)$ denote equivalent stiffness of gear shaft.
Kinetic energy of output shaft for the original system and chained system can be calculated as follows:

$$
\begin{gathered}
E=\frac{J_{3} \omega_{2}^{2}+J_{4} \omega_{2}^{2}}{2}, \\
E^{\prime}=\frac{J_{3}^{\prime} \omega_{1}^{2}+J_{4}^{\prime} \omega_{1}^{2}}{2},
\end{gathered}
$$

where $E$ is the kinetic energy of output shaft for the original system; $J_{3}$ and $J_{4}$ are the equivalent moments of inertia for the original system, which are derived by dynamic balance theory; $\omega_{1}$ and $\omega_{2}$ are the angular velocities; $E^{\prime}$ is the kinetic energy of output shaft for the original system; and $J_{3}^{\prime}$ and $J_{4}^{\prime}$ are equivalent moments of inertia for the chained system.

From the conservation law of energy, the following relationships are obtained:

$$
\begin{aligned}
& E=E^{\prime}, \\
& J_{3}^{\prime}=\frac{J_{3}}{i^{2}} \\
& J_{4}^{\prime}=\frac{J_{4}}{i^{2}}
\end{aligned}
$$

where $i$ is drive ratio. 


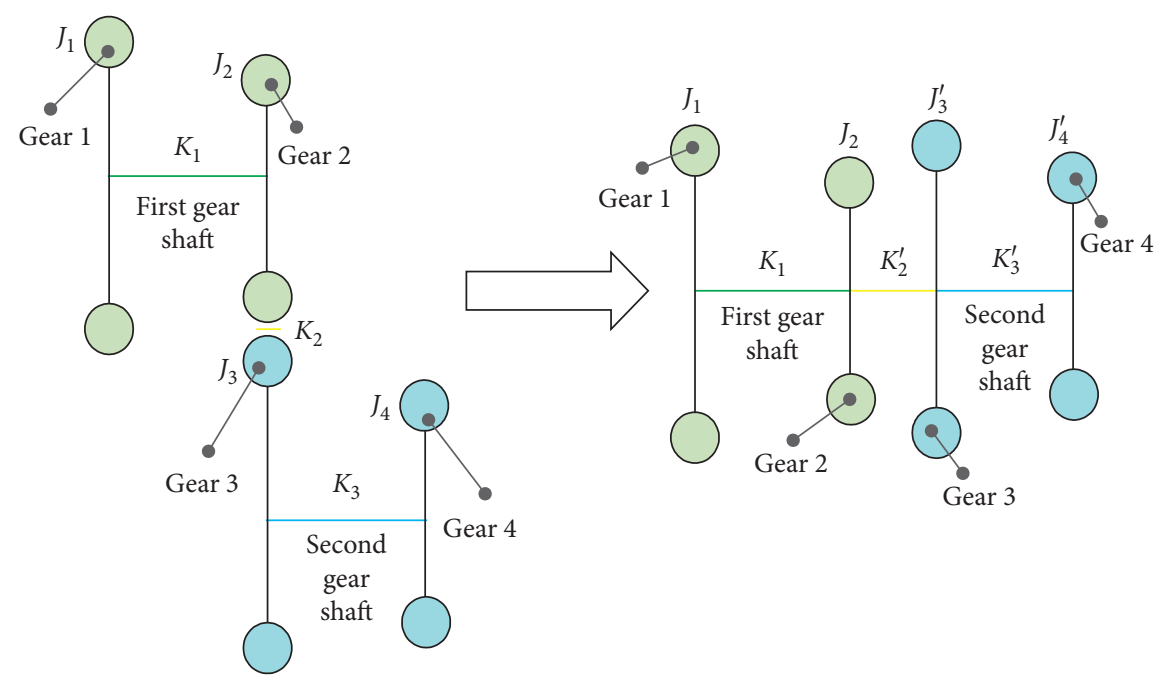

FIgURE 3: The schematic diagram of equivalent principle for simplifying a multimesh gear train into a chained system.

From the conservation of strain energy, an equation is derived:

$$
\frac{1}{2} K_{3}^{\prime} \varphi_{1}^{2}=\frac{1}{2} K_{3} \varphi_{2}^{2}
$$

where $K_{3}^{\prime}$ and $K_{3}$ are torsional stiffness of output shaft for the chained system and original system, respectively, and $\varphi_{1}$ and $\varphi_{2}$ are torsional angels of driving and driven shaft.

Owing to the assumption concerning a gear as rigid, the gear meshing stiffness, $K_{2}^{\prime}$ and $K_{2}$, is treated as infinite quantities. The following equations are derived:

$$
\left\{K_{3}^{\prime}=\frac{K_{3}}{i^{2}}, i=\frac{\varphi_{1}}{\varphi_{2}}, T_{2}^{\prime}=\frac{T_{2}}{i},\right.
$$

where $T_{2}^{\prime}$ is the input torque of output shaft and the $T_{2}$ is the output torque of input shaft.

According to preceding derivation, the equivalent moments of inertia for the chained system are calculated by

$$
\left\{\begin{array}{l}
J_{3}=I_{a 1}+\frac{I_{a 2}}{2}, \\
J_{4}=\frac{I_{a 2}}{2}+I_{g 1}, \\
J_{5}=\frac{\left(I_{b 1}+I_{g 2}+I_{b 2} / 2\right)}{i_{2: 1}^{2}}, \\
J_{6}=\frac{\left[\left(I_{b 2} / 2\right)+I_{g 3}+I_{b 3}+I_{g 4}+\left(I_{g 11} / i_{11: 4}^{2}\right)+I_{b 4}+I_{g 5}+\cdots+\left(I_{g 12} / i_{12: 5}^{2}\right)+I_{b 5}+I_{d}+I_{b 6}+I_{g 8}+\left(I_{g 9}+\left(I_{g 15} / i_{15: 9}^{2}\right) / i_{9: 8}^{2}\right)+I_{b 7}\right]}{i_{2: 1}^{2}}, \\
J_{7}=\frac{\left(\left(I_{c 1}+I_{d}+I_{g 10}+I_{c 2}+I_{c 3}+I_{c 4} / 2\right)+I_{d}\right)}{\left(i_{10: 3}^{2} \cdot i_{2: 1}^{2}\right)}, \\
J_{8}=\frac{\left[I_{c 4} / 2+I_{g 13}+I_{g 6} / i_{6: 13}^{2}+I_{c 5}+I_{g 14}+I_{g 7} / i_{7: 14}^{2}+I_{c 6}+I_{c 7}+I_{d}\right]}{\left(i_{10: 3}^{2} \cdot i_{2: 1}^{2}\right)},
\end{array}\right.
$$


where $I_{a j}(j=1,2)$ is the equivalent moment of inertia of the $j$ th node of input shaft; $I_{b j}(j=1,2, \ldots, 7)$ is the equivalent moment of inertia of the $j$ th node of middle shaft; $I_{c j}(j=$ $1,2, \ldots, 7)$ is the equivalent moment of inertia of the $j$ th node of output shaft; $I_{g j}(j=1,2, \ldots, 15)$ is the equivalent moment of inertia of $j$ th gear; $I_{d}$ is the equivalent moment of inertia of the synchronizer ring; and $i_{m: n}$ is the drive ratio of the mating gear pair.

2.3. Drive Shaft System. Drive shaft system comprises intermediate drive shaft, main drive shaft, three universal joints, and intermediate support. In this paper, the rotational inertia of shaft is equivalent to the universal joint by the lumped-mass method averagely. The lubrication, clearance, friction, manufacturing, and assembly errors, and flexibility of universal joint are not considered.
In order to describe the dynamics of a U-joint, a set of parameters are introduced as follows:

$$
\left\{\begin{array}{l}
A_{i}=\frac{1+\cos ^{2} \alpha_{i}}{2 \cos \alpha_{i}} \\
B_{i}=\frac{1-\cos ^{2} \alpha_{i}}{2 \cos \alpha_{i}} \\
i=1,2,3
\end{array}\right.
$$

where $\alpha_{i}(i=1,2,3)$ is the intersection angel between shafts linked by a universal joint (U-joint).

According to kinematics analysis, the following equations are derived:

$$
\begin{aligned}
& \left\{\begin{array}{l}
\theta_{9}=\arctan \frac{\tan \theta_{8}}{\cos \alpha_{1}}, \\
\theta_{9}^{\prime}=\frac{\theta_{8}^{\prime}}{A_{1}-B_{1} \cos 2 \theta_{8}}, \\
\theta_{9}^{\prime \prime}=\frac{\theta_{8}^{\prime \prime}}{A_{1}-B_{1} \cos 2 \theta_{8}}-\frac{2 B_{1} \sin 2 \theta_{8}}{\left(A_{1}-B_{1} \cos 2 \theta_{8}\right)^{2}}\left(\theta_{8}^{\prime}\right)^{2}, \\
T_{2}=\left(A_{1}-B_{1} \cos 2 \theta_{8}\right) T_{1},
\end{array}\right. \\
& \left\{\begin{array}{l}
\theta_{11}=\arctan \frac{\tan \theta_{10}}{\cos \alpha_{2}}, \\
\theta_{11}^{\prime}=\frac{\theta_{10}^{\prime}}{A_{2}-B_{2} \cos 2 \theta_{10}}, \\
\theta_{11}^{\prime \prime}=\frac{\theta_{10}^{\prime \prime}}{A_{2}-B_{2} \cos 2 \theta_{10}}-\frac{2 B_{2} \sin 2 \theta_{10}}{\left(A_{2}-B_{2} \cos 2 \theta_{10}\right)^{2}}\left(\theta_{10}^{\prime}\right)^{2}, \\
T_{4}=\left(A_{2}-B_{2} \cos 2 \theta_{10}\right) T_{3},
\end{array}\right. \\
& \left\{\begin{array}{l}
\theta_{13}=\arctan \frac{\tan \theta_{12}}{\cos \alpha_{3}}, \\
\theta_{13}^{\prime}=\frac{\theta_{12}^{\prime}}{A_{3}-B_{3} \cos 2 \theta_{12}}, \\
\theta_{13}^{\prime \prime}=\frac{\theta_{12}^{\prime \prime}}{A_{3}-B_{3} \cos 2 \theta_{12}}-\frac{2 B_{3} \sin 2 \theta_{12}}{\left(A_{3}-B_{3} \cos 2 \theta_{12}\right)^{2}}\left(\theta_{12}^{\prime}\right)^{2}, \\
T_{6}=\left(A_{3}-B_{3} \cos 2 \theta_{12}\right) T_{5},
\end{array}\right.
\end{aligned}
$$


where $\alpha_{1}$ is the intersection angel between output shaft of transmission and intermediate drive shaft; $\alpha_{2}$ is the intersection angel between main drive shaft and intermediate drive shaft; $\alpha_{3}$ is the intersection angel between main drive shaft and input shaft of rear axle.

The equivalent moments of inertia for intermediate drive shaft and main drive shaft are calculated by

$$
\left\{\begin{array}{l}
J_{9}=J_{10}=\frac{1}{2 i_{1}^{2}} J_{\mathrm{ids}} \\
J_{11}=J_{12}=\frac{1}{2 i_{1}^{2}} J_{\mathrm{mds}}
\end{array}\right.
$$

where $i_{1}$ is the drive ratio of transmission; $J_{\text {ids }}$ is the moment of inertia of intermediate drive shaft; and $J_{\text {mds }}$ is the moment of inertia of main shaft.

Equivalent torsional stiffness $k$ and damping coefficient $c$ of shaft are given by

$$
\left\{\begin{array}{l}
k=\frac{M}{\phi}=\frac{G_{a p} \pi\left(D^{4}-d^{4}\right)}{32 L}, \\
c=2 \zeta \sqrt{\frac{k J_{a} J_{b}}{J_{a}+J_{b}}}
\end{array}\right.
$$

where $\zeta$ is the damping ratio and $J_{a}$ and $J_{b}$ are the equivalent moment of inertia of shaft end.

2.4. Rear Axle. In this paper, the main reducer system is simplified as a geared rotor-bearing system with bendingtorsional-lateral-rocking coupled vibration. Pinion shaft is simplified as two lumped masses linked by a spring-damping pair with infinite stiffness, and the differential assembly is modeled as a rigid part with a concentrated mass. Half-shafts are described by two mass-spring-damping pairs. Otherwise, pinion and gear are treated as rigid bodies within torsional vibration analysis.

The equivalent moments of inertia for rear axle are calculated by

$$
\left\{\begin{array}{l}
J_{13}=\frac{1 / 5 J_{\mathrm{ps}}}{i_{1}^{2}}, \\
J_{14}=\frac{4 / 5 J_{\mathrm{ps}}}{i_{1}^{2}}, \\
J_{15}=\frac{J_{\mathrm{d}}+0.5 J_{\mathrm{hs}}}{i_{1}^{2} i_{2}^{2}}, \\
J_{16}=J_{17}=\frac{0.5 J_{\mathrm{hs}}+J_{\mathrm{hs}}}{i_{1}^{2} i_{2}^{2}}
\end{array}\right.
$$

where $i_{1}\left(i_{1}=1.350\right)$ is the drive ratio of transmission, $i_{2}$ $\left(i_{2}=4.1\right)$ is the drive ratio of the main reducer; $J_{\mathrm{ps}}$ is the moment of inertia of pinion shaft; $J_{\mathrm{d}}$ is the moment of inertia of differential assembly; and $J_{\mathrm{hs}}$ is the moment of inertia of half-shaft.

Equivalent stiffness of bearing is expressed as [27]

$$
\left\{\begin{array}{l}
K_{r}=\frac{7.253 l_{1}^{0.8} z_{1}^{0.9} \cos ^{2.0} \alpha_{1} \cdot F_{a 0}^{0.1}}{\cos ^{0.1} \alpha_{1}} \\
K_{a}=29.011 l_{1}^{0.8} \cos ^{1.9} \alpha_{1} \cdot F_{a 0}^{0.1},
\end{array}\right.
$$

where $K_{r}$ is the equivalent radial stiffness of bearing; $K_{a}$ is the equivalent axial stiffness of bearing; $l_{1}$ is the nominal contact length; $z_{1}$ is the number of rolling element; $\alpha_{1}$ is the pressure angle; and $F_{a 0}$ is the pretightening force.

In addition, a new model for pinion shaft is proposed, which is different from previous works. Owing to negligible elastic deformation, pinion shaft is modeled as rigid body. Bearing is modeled as a spring-damping pair. Without loss of generality, the derivation procedure on displacements of the mounting point in the $x$-o-y plane is used as an example.

In Figure $4, X_{p x}$ and $X_{p y}$ are introduced to represent translational displacements for centroid of pinion shaft; $\theta_{p z}$ denotes rocking displacement around the $z$ axis.

From the geometry deformation relationship and proposed concepts, the displacement for mounting point is calculated by

$$
\left\{\begin{array}{l}
x_{p y 1}=x_{p y}-l_{p 1} \tan \theta_{p z} \\
x_{p y 2}=x_{p y}-l_{p 2} \tan \theta_{p z}
\end{array}\right.
$$

Thereby, the following expressions are derived:

$$
\left\{x_{p y 1}^{\prime}=x_{p y}^{\prime}-l_{p 1} \frac{\theta_{p z}^{\prime}}{\cos ^{2} \theta_{p z}}, x_{p y 2}^{\prime}=x_{p y}^{\prime}-l_{p 2} \frac{\theta_{p z}^{\prime}}{\cos ^{2} \theta_{p z}} .\right.
$$

Static transmission error $e(t)[22-26,28]$ is simulated in Fourier series form by

$$
e(t)=e_{m}+\sum_{i=1}^{N} e_{A i} \cos \left(i \omega_{m} t+\varphi_{e}\right)
$$

where $e_{m}$ is the average value of transmission error; $e_{A i}$ are the amplitude of the $i$ th order harmonic; $\varphi_{e}$ are the initial phase angle of the $i$ th order harmonic; and $\omega_{m}$ is the meshing frequency.

The dynamic meshing stiffness is the periodically timevarying parameter with respect to the mesh frequency as shown in Figure 5, which can be simulated by means of a Fourier expansion [13, 14, 22-26]:

$$
k_{m}(t)=k_{m}+\sum_{i=1}^{N} k_{A i} \cos \left(i \omega_{m} t+\varphi_{k}\right)
$$

where $k_{m}$ is the mean value of meshing stiffness, $k_{A i}$ is the fluctuation amplitude of $i$ th order meshing stiffness, $\omega_{m}$ is the mesh frequency, and $\varphi_{k}$ is the initial phase of meshing stiffness.

Defining $m_{e}$ denotes mean mass of pinion and gear: 


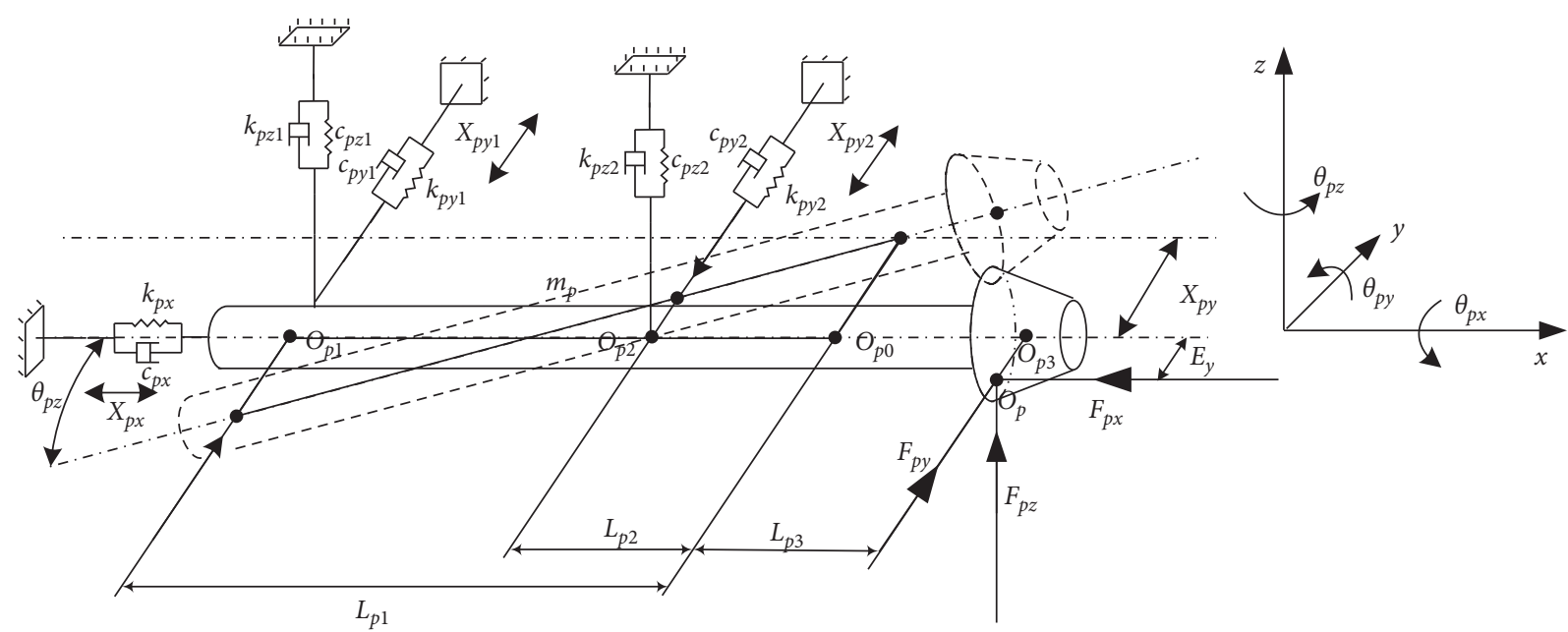

FIgURE 4: The dynamic model of pinion shaft.

$$
m_{e}=\frac{1}{\left(1 / m_{p}\right)+\left(1 / m_{g}\right)}=\frac{m_{p} m_{g}}{m_{p}+m_{g}} .
$$

The following equation can be derived:

$$
\omega_{n}=\sqrt{\frac{k_{m}}{m_{e}}},
$$

where $\omega_{n}$ is the equivalent natural frequency of pinion and gear.

Equivalent mesh damping coefficient is calculated, which is different from Wang and Lim's analysis [25]:

$$
c_{m}=\xi * 2 m_{e} \omega_{n}=2 \xi \sqrt{\frac{k_{m}}{\left(1 / m_{p}\right)+\left(1 / m_{g}\right)}},
$$

where $\zeta$ is the damping ratio, generally set as a range of 0.03 to 0.17 [25]; $m_{p}$ and $m_{g}$ are equivalent mass of pinion and gear, respectively.

The relative displacement along the normal direction at the meshing point $x_{n}$ is given as follows:

$$
\begin{aligned}
x_{n}= & {\left[\left(x_{p x}+E_{y} \theta_{p z}\right)-\left(x_{g x}+E_{z} \theta_{g y}+l_{g 3} \theta_{g z}\right)\right] } \\
& \cdot\left(\cos \alpha_{n} \sin \beta_{m} \cos \delta_{1}+\sin \alpha_{n} \sin \delta_{1}\right) \\
& +\left[\left(x_{p y}+l_{p 3} \theta_{p z}\right)-\left(x_{g y}+E_{z} \theta_{g x}-E_{x} \theta_{g z}\right)\right] \\
& \cdot\left(-\cos \alpha_{n} \sin \beta_{m} \sin \delta_{1}+\sin \alpha_{n} \cos \delta_{1}\right) \\
& +\left[\left(x_{p z}-R_{p} \theta_{p x}+l_{p 3} \theta_{p y}\right)-\left(x_{g z}-l_{g 3} \theta_{g x}-R_{g} \theta_{g y}\right)\right] \\
& \cdot\left(\cos \alpha_{n} \cos \beta_{m}\right)-e(t) \\
= & \varepsilon_{1}\left(x_{p x}-x_{g x}-E_{z} \theta_{g y}+E_{y} \theta_{p z}-l_{g 3} \theta_{g z}\right) \\
& +\varepsilon_{2}\left(x_{p y}-x_{g y}-E_{z} \theta_{g x}+l_{p 3} \theta_{p z}+E_{x} \theta_{g z}\right) \\
& +\varepsilon_{3}\left(x_{p z}-x_{g z}-R_{p} \theta_{p x}+l_{g 3} \theta_{g x}+l_{p 3} \theta_{p y}+R_{g} \theta_{g y}\right) \\
& -e(t) .
\end{aligned}
$$

The backlash function is expressed as [23]

$$
f\left(x_{n}\right)= \begin{cases}x_{n}-b, & x_{n} \geq b, \\ 0, & -b \leq x_{n} \leq b, \\ x_{n}+b, & x_{n} \leq-b,\end{cases}
$$

where $b$ is half of gear backlash.

The dynamic meshing force along the line of action $F_{n}$ can be calculated by

$$
F_{n}=k_{m}(t) f\left(x_{n}\right)+c_{m} x_{n}^{\prime},
$$

where $c_{m}$ represents the value of equivalent mesh damping coefficient.

The components of dynamic mesh force along the coordinate directions are expressed as

$$
\left\{\begin{array}{l}
F_{x}=F_{n} \cos \alpha_{n} \sin \beta_{m} \cos \delta_{1}+F_{n} \sin \alpha_{n} \sin \delta_{1}, \\
F_{y}=-F_{n} \cos \alpha_{n} \sin \beta_{m} \sin \delta_{1}+F_{n} \sin \alpha_{n} \cos \delta_{1}, \\
F_{z}=F_{n} \cos \alpha_{n} \cos \beta_{m},
\end{array}\right.
$$

where $\delta_{1}$ is cone angle of the pinion; $\alpha_{n}$ is the normal pressure angle, and $\beta_{m}$ is the helix angle at the midpoint of the pinion.

In additional, the following equations are derived by introducing the parameter $\varepsilon_{i}$ :

$$
\left\{\begin{array}{l}
\varepsilon_{1}=\cos \alpha_{n} \sin \beta_{m} \cos \delta_{1}+\sin \alpha_{n} \sin \delta_{1}, \\
\varepsilon_{2}=-\cos \alpha_{n} \sin \beta_{m} \sin \delta_{1}+\sin \alpha_{n} \cos \delta_{1}, \\
\varepsilon_{3}=\cos \alpha_{n} \cos \beta_{m} .
\end{array}\right.
$$

Substituting equations (26) into (25), the expressions of dynamic mesh force applied on pinion and gear can be written as

$$
\left\{\begin{array}{l}
F_{p x}=-F_{g x}=\varepsilon_{1} F_{n} \\
F_{p y}=-F_{g y}=\varepsilon_{2} F_{n} \\
F_{p z}=-F_{g z}=\varepsilon_{3} F_{n}
\end{array}\right.
$$

where the subscript $p$ is the label for pinion and the subscript $g$ is the label for gear.

Mesh impact due to teeth separation is neglected in this paper.

2.5. Equations of Motion. From the preceding derivations, the equations of motion considering bending-torsionallateral-rocking vibration are expressed as 


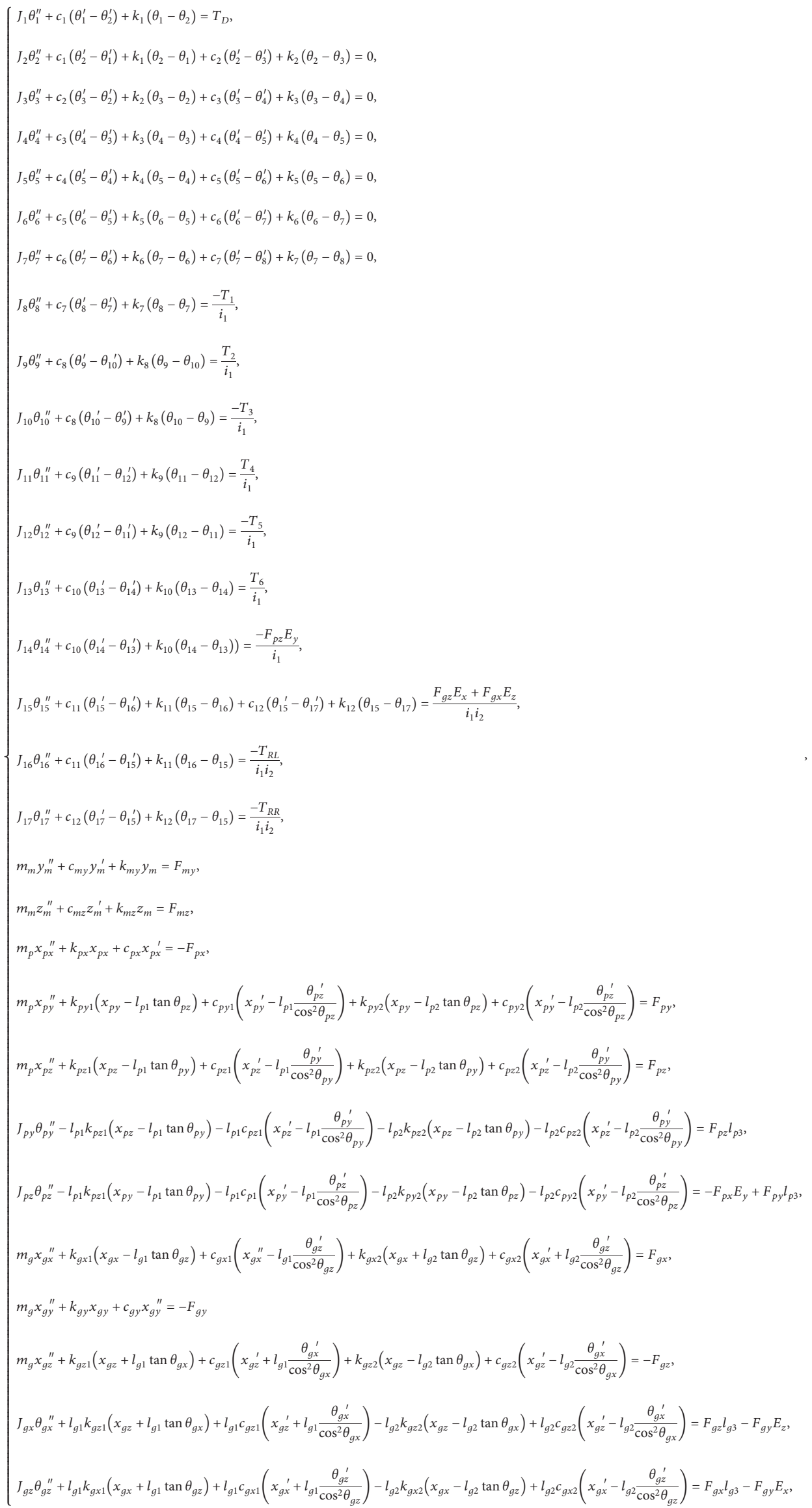


where $T_{\mathrm{D}}$ is the input torque of motor; $T_{1}$ is the output torque of transmission; $T_{2}$ and $T_{3}$ are the input and output torque for intermediate drive shaft; $T_{4}$ and $T_{5}$ are the input and output torque for main drive shaft; $T_{6}$ is the input torque of rear axle; $k_{i}(i=1,2, \ldots, 7)$ are the equivalent torsional stiffness; $c_{i}(i=1,2, \ldots, 7)$ are the equivalent torsional damping; $k_{i}(i=8,9)$ are the equivalent torsional stiffness; $c_{i}(i=8,9)$ are the equivalent torsional damping; $m_{\mathrm{m}}$ is the mass of transmission shaft; $k_{i}(i=10,11,12)$ are the equivalent torsional stiffness for pinion shaft and differential axle; $c_{i}(i=10,11,12)$ are the equivalent torsional damping for pinion shaft and differential axle; $c_{m y}$ and $c_{m z}$ are the equivalent damping of intermediate support along axes $y$ and $z ; k_{m y}$ and $k_{m z}$ are the equivalent stiffness of intermediate support along axes $y$ and $z ; F_{m y}$ and $F_{m z}$ are components of additional force $F_{i}$ along axes $y$ and $z$ for intermediate support; $E_{i}(i=x, y, z)$ are coordinates of meshing point along axes $x, \mathrm{y}$, and $z$; and $T_{R L}$ and $T_{R R}$ are load torque for wheels.

2.6. Numerical Solution Procedure. The fourth-order adaptive step Runge-Kutta method which is generally applicable to strong nonlinearity is adopted in the present work to solve the equations. In order to program, a new state space is needed.

In consideration of equations (12)-(14), it can be derived that kinetic equations of 3 universal joints reduce the number of degree-of-freedom from 29 to 26 for the whole system. The following state space coordinate vector also describes the dynamic behaviors of the system:

$$
\{S s\}=\left\{\begin{array}{c}
\theta_{1}, \theta_{2}, \theta_{3}, \theta_{4}, \theta_{5}, \theta_{6}, \theta_{7}, \theta_{8}, \theta_{10}, \theta_{12}, \theta_{14}, \theta_{15}, \theta_{16}, \theta_{17} \\
\theta_{p y}, \theta_{p z}, \theta_{g x}, \theta_{g z}, y_{m}, z_{m}, x_{p}, y_{p}, z_{p}, x_{g}, y_{g}, z_{g}
\end{array}\right\}^{\mathrm{T}} .
$$

In order to eliminate the difference in magnitude between parameters, which will reduce the solvability and even lead to no convergence for solving equations of motion mentioned above, $b$ is defined as the characteristic length and a new time parameter $\tau$ is introduced as follows:

$$
\tau=t \omega_{n},
$$

where $t$ denotes time.

For the sake of nominalizing equations, a generalized state space coordinate vector with 26 parameters is proposed to characterize dimensionless equations as

$$
\{s t\}=\left\{s_{r 1}, s_{r 2}, s_{r 3}, s_{r 4}, s_{r 5}, s_{r 6}, s_{r 7}, s_{r 8}, s_{r 10}, s_{r 12}, s_{r 16}, s_{r 17}, s_{r p x}, s_{r p y}, s_{r p z}, s_{r g x}, s_{r g y}, s_{r g z}, s_{m y}, s_{m z}, s_{p x}, s_{p y}, s_{p z}, s_{g x}, s_{g y}, s_{g z}\right\}^{T} .
$$

The following equations are derived as

$$
\left\{\begin{array}{l}
s_{r i}=\theta_{i} \times \frac{R_{i}}{b}, \quad i=1 \sim 8,10,12,16,17, \\
s_{r p x}=\theta_{14} \times \frac{R_{p x}}{b}, \\
s_{r g y}=\theta_{15} \times \frac{R_{g y}}{b}, \\
s_{r i j}=\theta_{i j} \times \frac{R_{i j}}{b}, \quad i=p, g ; j=x, y, z, \\
s_{i x}=\frac{x_{i}}{b}, \quad i=p, g, \\
s_{i y}=\frac{y_{i}}{b}, \quad i=m, p, g, \\
s_{i z}=\frac{z_{i}}{b}, \quad i=m, p, g,
\end{array}\right.
$$

where $b$ is the half of backlash and $R_{i}$ is the equivalent gyration radius, which can be calculated by the following equation:

$$
\left\{\begin{array}{l}
R_{i}=\sqrt{\frac{J_{i}}{m_{i}}}, \quad i=1 \sim 8,10,12,16,17, \\
R_{i j}=\sqrt{\frac{J_{i j}}{m_{i}}}, \quad i=p, g ; j=x, y, z,
\end{array}\right.
$$

where $J_{i}$ and $J_{i j}$ are the equivalent moment of inertia and $m_{i}$ is equivalent mass.

A set of dimensionless parameters are defined as

$$
\left\{\begin{array}{l}
x_{n \tau}=\frac{x_{n}}{b} ; \\
f\left(x_{n \tau}\right)=\frac{f\left(x_{n}^{t}\right)}{b} ; \\
c_{(i, j, s)}=\frac{c_{i}}{m_{j} R_{j} R_{s} \omega_{n}} ; \\
k_{(i, j, s)}=\frac{k_{i}}{m_{j} R_{j} R_{s} \omega_{n}^{2}} ; \\
c_{m i}=\frac{c_{m}}{m_{i} \omega_{n}} ; \\
k_{m i}=\frac{k_{m}}{m_{i} \omega_{n}^{2}} ; \\
T_{(x, j)}=\frac{T_{x}}{m_{j} R_{j} \omega_{n}^{2} b} ; \\
l_{i j \tau}=\frac{l_{i j}}{b} .
\end{array}\right.
$$

As equations (30), (32), and (34) are substituted into equation (28), the dimensionless equations of motion can be derived. 
The equivalent inertia parameters are obtained in UG, and stiffness parameters of powertrain are calculated by using the relationships given in modeling section as listed in Table 1. Subsequently, equivalent damping coefficients can be obtained. The parameters of the main reducer can be calculated by substituting system parameters listed in Table 2 into equations (17)-(31). The solution procedures for dimensionless parameter are carried out by using preceding calculated parameters and the relationships proposed in previous parts.

The exciting and configuration parameters are set as $\theta_{1}=1500 \mathrm{rpm}, T_{d 2}=100 \mathrm{~N} \cdot \mathrm{m}, k_{m}=9.697 e 8 \mathrm{~N} / \mathrm{m}, i_{1}=1.35$, $i_{2}=4.1,2 b=0.15 \mathrm{~mm}, e_{m}=0, \alpha_{1}=1.695$ degree, $\alpha_{2}=1.3044$ degree, and $\alpha_{3}=1.554$ degree, respectively. Without significant loss of accuracy, the fundamental harmonic form is adopted for time-varying mesh stiffness and static transmission error function whose initial phases are set at 0 , respectively.

\section{Numerical Results}

3.1. Analysis of Coupled Torsional Vibration. In order to analysis coupled interaction of automotive powertrain, Fourier spectrums of torsional vibration response are calculated at the initial parameters as shown in Figure 6. Two peaks and their sidebands are observed. The torsional vibrational responses are governed by the component of $50 \mathrm{~Hz}$ which equals with exciting frequency of input torque as shown in equation (3) $\left(\omega_{f}=1500 / 60 * 2=50 \mathrm{~Hz}\right)$. This implies that engine input excitation is responsible for torsional vibration and a valuable approach to decreasing torsional vibration of powertrain is inferred. In addition, the component with a frequency of around $185 \mathrm{~Hz}$ is observed obviously for each considered part. As one knows, the meshing frequency undergoing this condition is presumably $185.185 \mathrm{~Hz}(f=1500 / 60 / 1.35=185.185 \mathrm{~Hz})$ which is quite in agreement with the frequency of the second peak. Coupled vibration occurs between the torsional system and hypoid gear set, and inner excitation caused by gear pair meshing process which is affected by clearance and time-varying meshing stiffness [25] accounts a lot for torsional vibration at $185 \mathrm{~Hz}$ of powertrain and affects torsional responses slightly. After simply calculation, bandwidths reaching the same value of around $37 \mathrm{~Hz}$ of sidebands around two peaks are got. U-joint is a transmission mechanism with nonconstant angular speed which will excite a doubled frequency torsional vibration of input as shown in equations (12)-(14). Under this condition, the doubled frequency excited by $\mathrm{U}$-joint is calculated:

$$
f_{\mathrm{u}-\text { joint }}=\frac{n}{i_{1} * 60} * 2=\frac{1500}{1.35 * 60} * 2=37.04 .
$$

It can be conjectured that modulation phenomenon appears when automotive powertrain works between excitations attributed to input, U-joint, and gear pair. As one can see in Figure 6, compared torsional response of gear with that located front of meshing point, a lower value of torsional angular is observed, and it is inferred that gear mesh excitations reduce torsional vibration for components located behind meshing point. It is noted that taking gear mesh behaviors into account is quite necessary to when a torsional characteristic analysis is conducted.

\subsection{Amplitude-Frequency Response of Torsional Vibration for} Automotive Powertrain. The previous works [29] analyzed torsional characteristics of the coupled system consisted of drive shaft and rear axle, which denoted that resonance of drive shaft at the first two-order nature frequency accounts for dramatic torsional vibration responses undergoing highrotation-speed condition. However, it cannot reveal the torsional vibration mechanism of automotive under lowand middle-speed condition.

In order to obtain a more realistic understanding for amplitude-frequency response of automotive powertrain undergoing middle-speed condition theoretically, the preceding equations of motion are adopted. A sweep frequency analysis procedure is carried out in a range from $1000 \mathrm{rpm}$ to $3500 \mathrm{rpm}$, which, respectively, corresponds to frequency internal of $16.6-58.3 \mathrm{~Hz}$ for input speed, 33.33-116.7 Hz for input excitation, and $123.46-432.09 \mathrm{~Hz}$ for meshing excitation. The response at input end of rear axle is taken as an example in this work.

Figure 7 shows the amplitude-frequency response, in which abscissa denotes torsion speed of input and ordinate is RMS value of angular displacement. As one can see, three obvious peaks which correspond to input speed at about $1000 \mathrm{rpm}, 1600 \mathrm{rpm}$, and $2800 \mathrm{rpm}$, respectively, are observed. Owing to the assumption that the dramatic responses are attributed to resonance of the system, the first threeorder nature frequency respect to the second-order term of input torque fluctuation is proposed at $33.3 \mathrm{~Hz}, 53.3 \mathrm{~Hz}$, and 93.3 Hz successively. It is noted that on the basis of previous analysis, these three peaks also correspond to frequencies of $24.7 \mathrm{~Hz}, 39.5 \mathrm{~Hz}$, and $69.1 \mathrm{~Hz}$ for the U-joint excitation and 123.4 Hz, 197.5 Hz, and $345.6 \mathrm{~Hz}$ for the meshing excitation. Preliminary works [29] showed that resonance is attributed to input excitation of drive shaft and the meshing excitation of hypoid gear pair with higher exciting frequency than input will not excite prominent resonance behaviors of drive shaft as illustrated in Figure 8, i.e., meshing excitation has slight influence on the torsional system, which reaches the same conclusion with this work. According to analysis in Section 3.1, the sidebands respect to each exciting frequency are $(8.6-58) \mathrm{Hz}$ at $33.3 \mathrm{~Hz},(13.8-92.8) \mathrm{Hz}$ at $53.3 \mathrm{~Hz}$, and (24.2-162.4) Hz at 93.3 Hz for input torque, and (98.7-148.1) $\mathrm{Hz}$ at $123.4 \mathrm{~Hz},(158-237) \mathrm{Hz}$ at $197.5 \mathrm{~Hz}$, and (276.5-414.7) $\mathrm{Hz}$ at $345.6 \mathrm{~Hz}$ for meshing behavior of the gear pair, respectively. As listed in Table 3, the first peak can be attributed to the first two-order resonances of drive shaft excited by sideband around $123.4 \mathrm{~Hz}$. Sidebands at $53.3 \mathrm{~Hz}$ and $197.5 \mathrm{~Hz}$ result in the second-order resonance, which generates the second peak. Moreover, the second-order resonances excited by the sideband at $93.3 \mathrm{~Hz}$ and third-order one caused by sideband at $345.6 \mathrm{~Hz}$ explain the appearance of the third peak. A typical phenomenon is observed that the torsional vibration reduces a lot while one compares the amplitude of the third peak with another two, which 
TABLE 1: The equivalent parameters of powertrain.

\begin{tabular}{lcc}
\hline Equivalent mass $(\mathrm{kg})$ & Equivalent moment of inertia $\left(\mathrm{kg} \cdot \mathrm{m}^{2}\right)$ & Equivalent stiffness $(\mathrm{N} / \mathrm{m})$ \\
\hline$m_{1}=2$ & $J_{1}=0.091125$ & $k_{1}=10023.75$ \\
$m_{2}=10$ & $J_{2}=0.3801735$ & $k_{2}=1640.25$ \\
$m_{3}=0.6150$ & $J_{3}=0.00008103$ & $k_{3}=27500$ \\
$m_{4}=1.3798$ & $J_{4}=0.001001$ & $k_{4}=1.0 e 11$ \\
$m_{5}=2.3581$ & $J_{5}=0.001323$ & $k_{5}=479000$ \\
$m_{6}=11.4323$ & $J_{6}=0.00249$ & $k_{6}=1.0 e 11$ \\
$m_{7}=4.5323$ & $J_{7}=0.001865$ & $k_{7}=21400$ \\
$m_{8}=7.5567$ & $J_{8}=0.002098$ & - \\
$m_{9}=1.284$ & $J_{9}=0.001695$ & $k_{8}=43921.799$ \\
$m_{10}=1.284$ & $J_{10}=0.001695$ & - \\
$m_{11}=1.3125$ & $J_{11}=0.00173$ & $k_{9}=41933.635$ \\
$m_{12}=1.3125$ & $J_{12}=0.00173$ & - \\
$m_{13}=0.4254$ & $J_{13}=0.00002772$ & $k_{10}=1.0 e 11$ \\
$m_{14}=1.7016$ & $J_{14}=0.0001109$ & $k_{m}=9.6965 e 8$ \\
$m_{15}=13.75$ & $J_{15}=0.034177$ & - \\
$m_{16}=8.45$ & $J_{16}=9.9$ & $k_{11}=12032.114$ \\
$m_{17}=8.45$ & $J_{17}=9.9$ & $k_{12}=12032.114$ \\
\hline
\end{tabular}

TABLE 2: The system parameters of the main reducer.

\begin{tabular}{|c|c|c|}
\hline Parameter & Pinion & Gear \\
\hline Number of teeth & 10 & 41 \\
\hline Module (mm) & & \\
\hline Mean pressure angle (deg.) & 20 & 20 \\
\hline Helix angle at midpoint of the pinion (deg.) & 50 & 27.13 \\
\hline Cone angle (deg.) & 23.12 & 65.14 \\
\hline Tooth width $(\mathrm{mm})$ & 40.66 & 34.52 \\
\hline Tooth addendum (mm) & 3.59 & 6.44 \\
\hline Pinion outset $(\mathrm{mm})$ & & \\
\hline Mounting distance (mm) & 112 & 64 \\
\hline Pitch radius $(\mathrm{mm})$ & 40 & 108 \\
\hline Backlash $(\mathrm{mm})$ & & \\
\hline Distance from pinion reference point to the $x-o-z$ plane for pinion $(\mathrm{mm})$ & & \\
\hline Distance from pinion reference point to the $y-o-z$ plane for gear $(\mathrm{mm})$ & & \\
\hline Distance between projection point and centroid of pinion shaft $(\mathrm{mm})$ & $l_{p 3}=10$ & $l_{q 3}=5$ \\
\hline Distance between bearing reference point and centroid of pinion shaft $(\mathrm{mm})$ & $\begin{array}{l}l_{p 1}=100 \\
l_{p 2}=17.5\end{array}$ & $\begin{array}{l}l_{g 1}=90 \\
l_{g 2}=93\end{array}$ \\
\hline Equivalent mass $(\mathrm{kg})$ & $\begin{array}{c}m_{g}=2.127 \\
J_{p x}=J_{14}\end{array}$ & $\begin{array}{c}m_{p}=13.75 \\
J_{g x}=0.050315\end{array}$ \\
\hline Equivalent moment of inertia $\left(\mathrm{kg} \cdot \mathrm{m}^{2}\right)$ & $\begin{array}{l}J_{p y}=0.002982 \\
J_{p z}=0.002982\end{array}$ & $\begin{array}{c}J_{g x}=J_{15} \\
J_{p z}=0.037551\end{array}$ \\
\hline
\end{tabular}

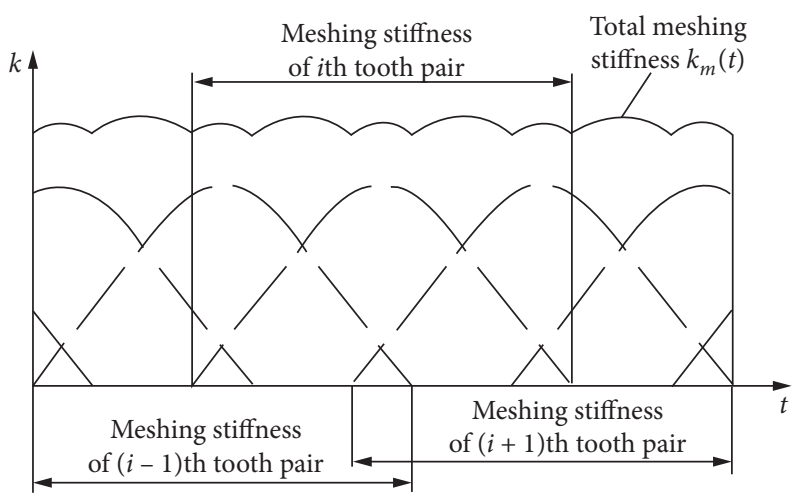

FIGURE 5: Schematic diagram of time-varying meshing stiffness on hypoid gear. 


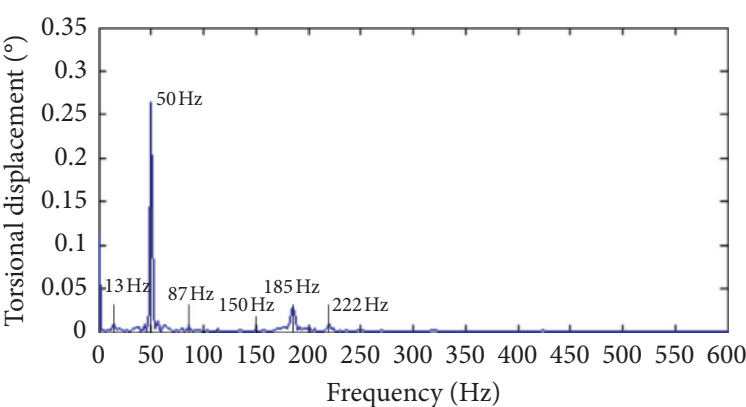

(a)

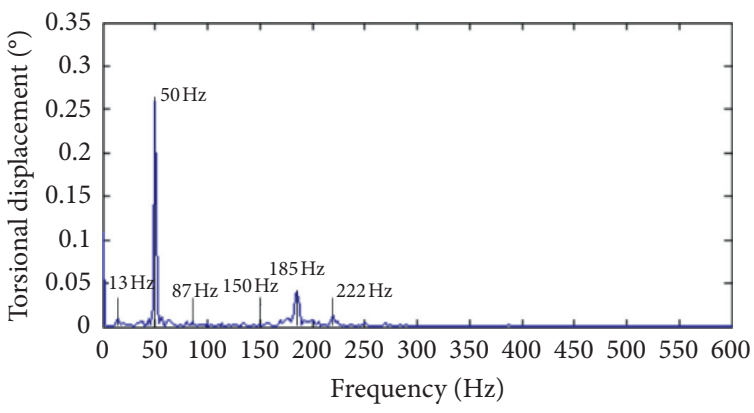

(c)

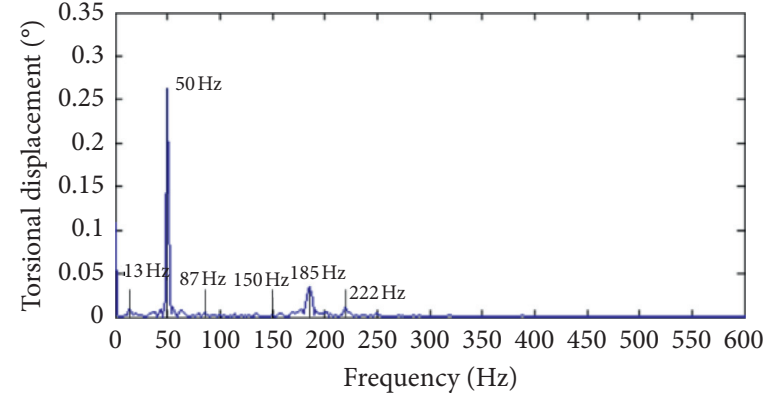

(b)

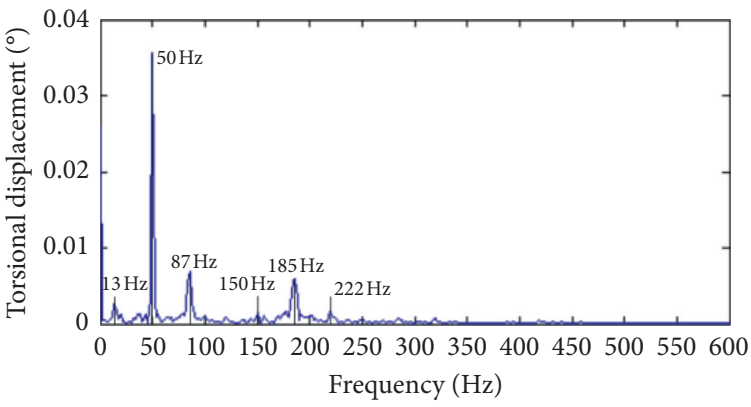

(d)

FIgURE 6: The Fourier spectrum of torsional responses: (a) output shaft of transmission; (b) output end of the drive shaft system; (c) torsional displacement of the pinion along the axis $x$; (d) torsional displacement of the gear along the axis $y$.

indicates that torsional behaviors of automotive powertrain affect the vibration characteristics of the complete vehicle under a low- or middle-input-speed condition. In order to validate the preceding result, an experimental study is necessary.

\section{Experimental Analysis}

A test bench which can be used to test the vibration behavior of a transmission system used for four-wheel drive vehicle belonging to the China Automotive Technology and Research Center is adopted to perform this experiment. There are five motors in the test bench, and three of them are used in this experiment. One of them drives automotive powertrain, which can generate a high frequency input torque with fluctuation varied in accordance with necessary, and others are used as loads. In this test, two photoelectric sensors and two magnetoelectric sensors are used to detect torsional vibration signals, and other five accelerometers are mounted to monitor transverse vibration. Installation site for each sensor can be found in Figure 9. Signals are sampled and processed by LMS Test.Lab.

In order to validate the feasibility of the theoretical model, the input torque simulated by input motor and loads are consistent with parameters employed in numerical analysis (mean value and the second-order term are contained only, and fluctuation amplitude is set at $100 \mathrm{~N} \cdot \mathrm{M}$ for input torque). Within the experiment, the output speed of motor varies from $1000 \mathrm{rpm}$ to $3500 \mathrm{rpm}$ to conduct a sweep frequency response analysis experimentally.

As illustrated in Figure 10, the amplitude-frequency responses of torsional vibration have the similar feature for different parts of powertrain. Peaks can be observed for carves at a similar input speed. It is inferred that a presume resonance occurs at each peak. As a result, the first threeorder nature torsional frequencies can be predicted. Meanwhile, the same results are reached. As shown in Figure 10, each curve has a higher value nearby the first and second peak. With the further increase in frequency, it reaches a lower plateau value. Torsional behaviors have an effect on the vibration characteristics under a low-inputspeed condition. Furthermore, the part located behind the mesh point, such as output end of half-shaft, has a lower RMS value than transmission and drive shaft, which can be attributed to reduction effect of mesh excitation on torsional vibration.

The experimental result of input end of rear axle is compared with the numerical one. As shown in Figure 11, a quite consistency is observed and the first three-order frequencies are inferred at $35 \mathrm{~Hz}(1050 \mathrm{rpm}), \quad 55.7 \mathrm{~Hz}$ (1670 rpm), and $88.3 \mathrm{~Hz}(2650 \mathrm{rpm})$ for experimental result by the same way mentioned in preceding section. Compared with numerical predictions, an acceptable difference of about $5 \%$ (the difference is $5.1 \%$ at $33.3 \mathrm{~Hz}, 4.5 \%$ at $53.3 \mathrm{~Hz}$, and $5.36 \%$ at $93.3 \mathrm{~Hz}$ ) can be obtained. These indicate that the theoretical model is feasible for predicting nature torsional frequencies. Moreover, numerical torsional displacement is a little lower than the experimental one at the same input speed which is below about $2450 \mathrm{rpm}$, and a little higher with the further increase. This can be presumably attributed to assumptions made in this present work with respect to the complexity of the system and the limitations of the lumped-mass method. 


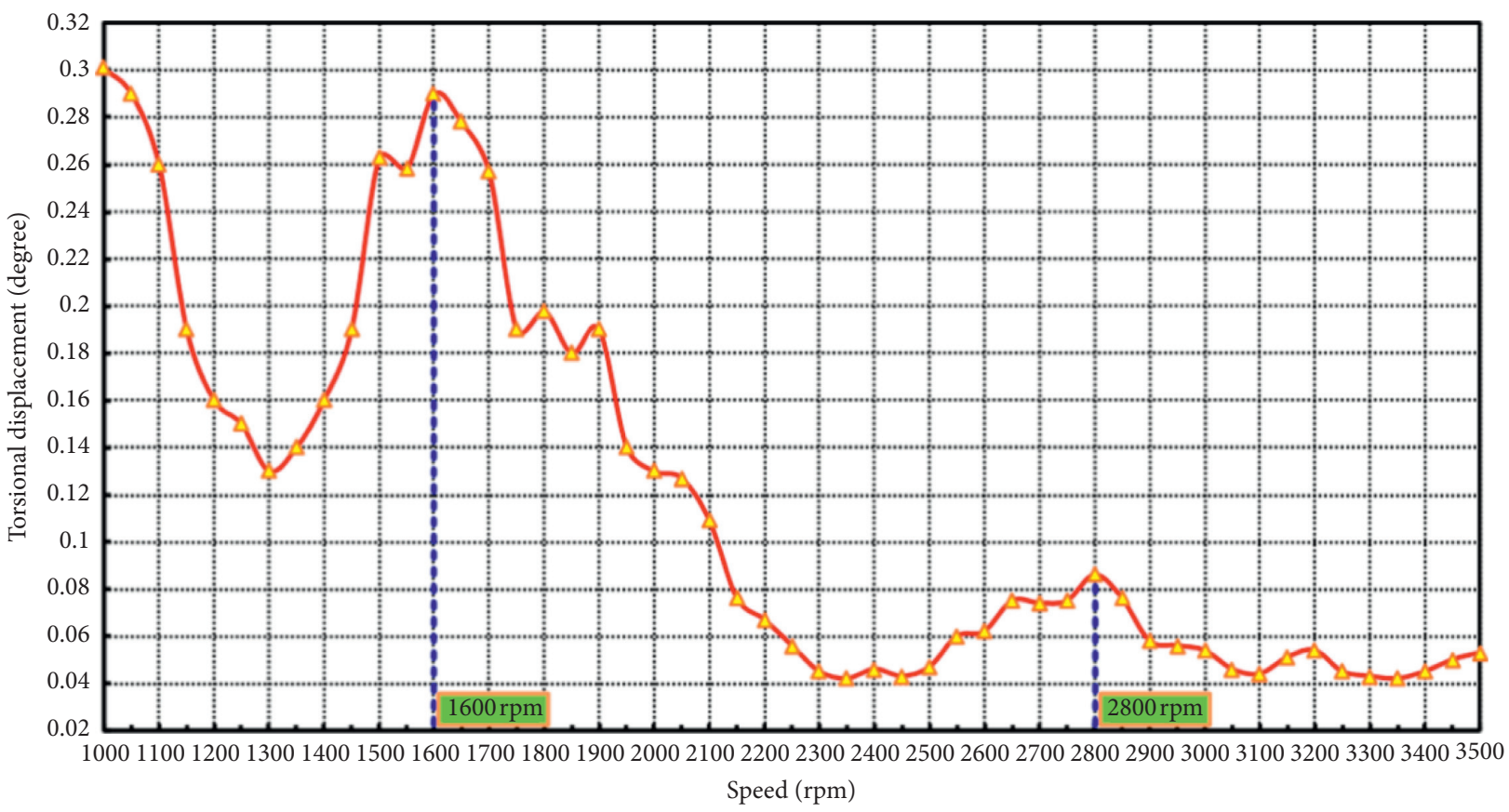

FIGURE 7: Amplitude-frequency response at input end of rear axle.

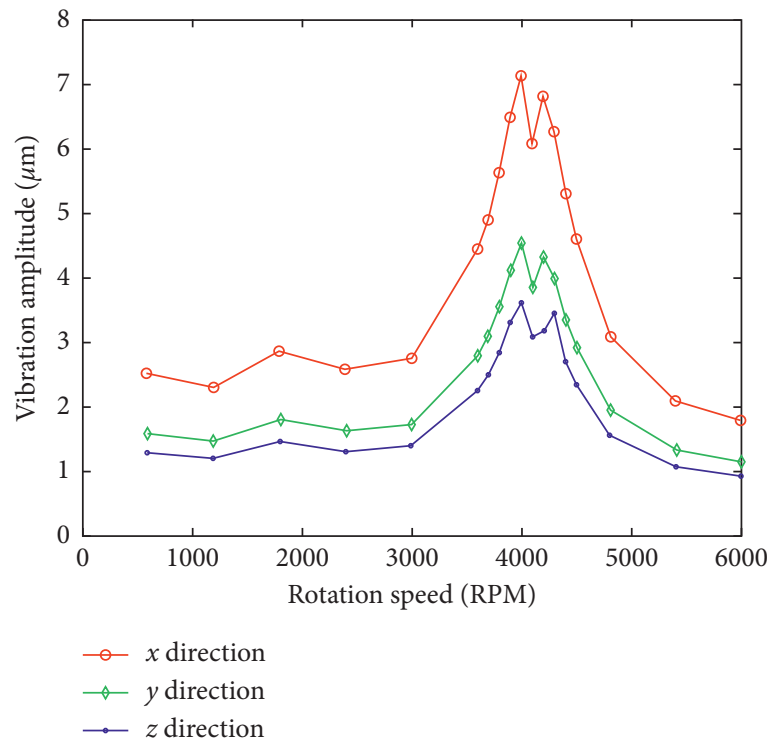

FIGURE 8: Influence of input rotation speed of drive shaft on vibration of the main reducer [29].

TABLE 3: The first six-order nature frequency of drive shaft [29].

\begin{tabular}{lcccccc}
\hline Order & 1 & 2 & 3 & 4 & 5 & 5 \\
\hline Frequency $(\mathrm{Hz})$ & 130.9 & 140.2 & 415.2 & 442.2 & 636.2 & 906.6 \\
\hline
\end{tabular}

The previous section indicates numerically that excitation of input dominates torsion vibration of the system and gear set affects responses slightly. In order to validate the correctness of numerical analysis and feasibility decreasing torsional vibration by reducing input excitation, effect of input torque fluctuation on torsional response is studied experimentally. The mean value of input torque is set at $150 \mathrm{~N} \cdot \mathrm{M}$, and fluctuation of the second-order term is set at 


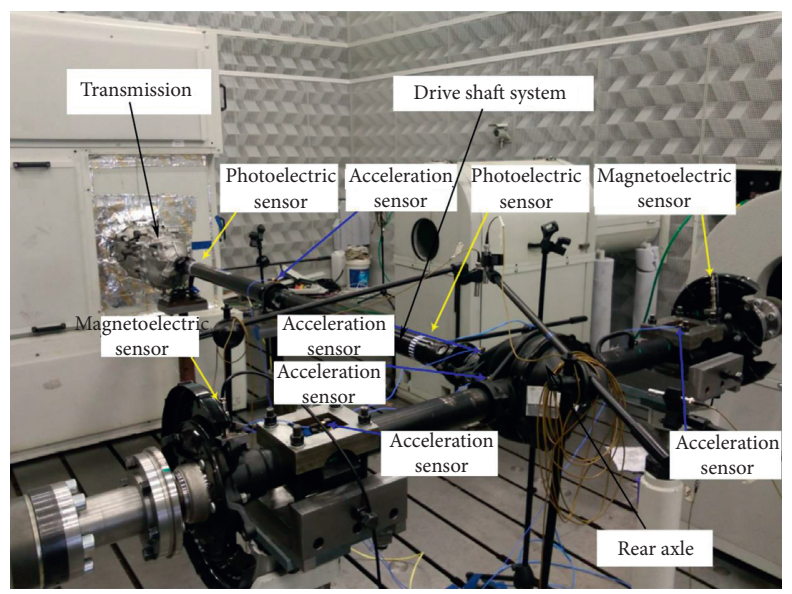

FIgURE 9: The experiment bench and arrangement of sensors.

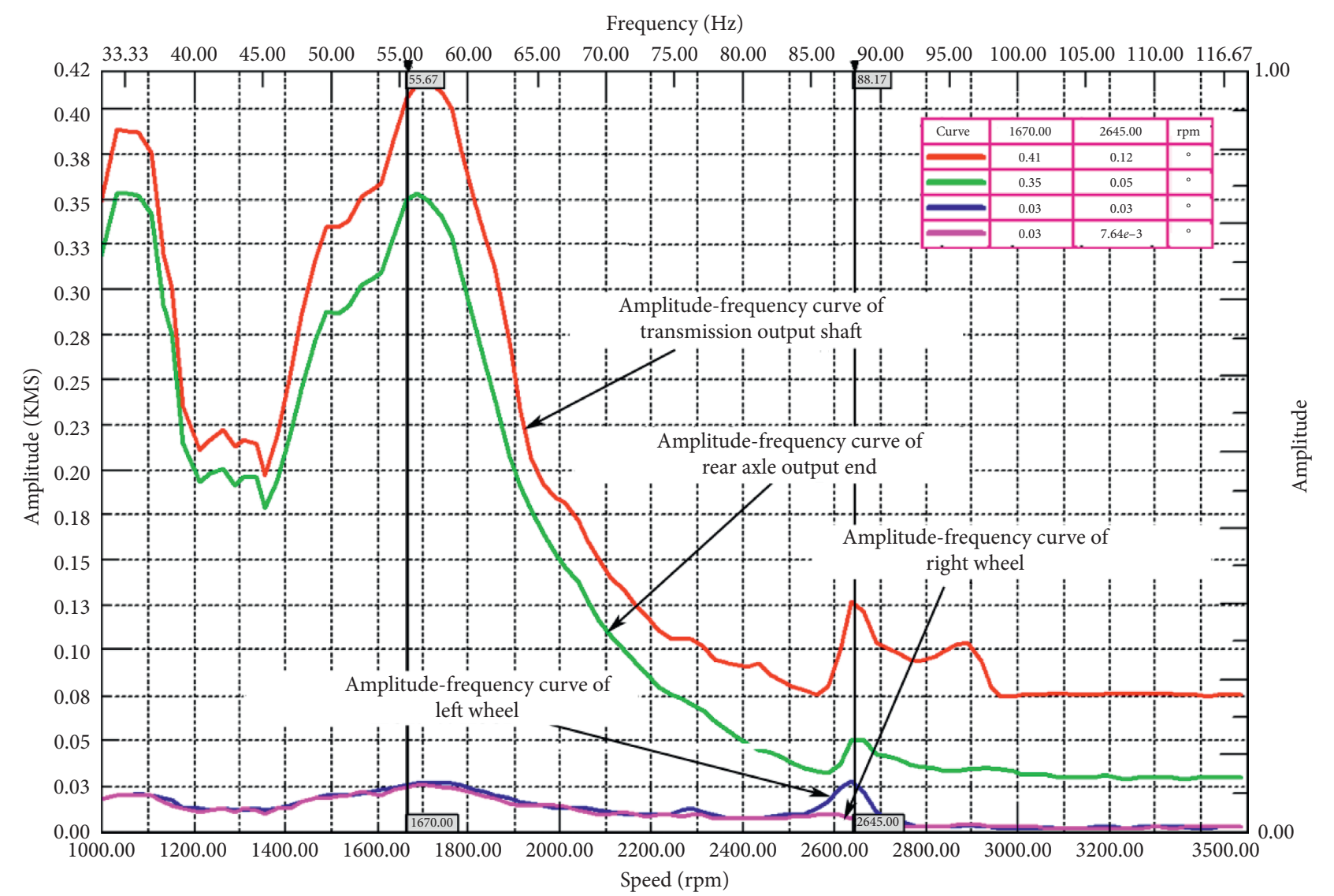

Figure 10: Amplitude-frequency responses of torsional vibration for powertrain at a torque fluctuation of $100 \mathrm{~N} \cdot \mathrm{M}$.

$25 \mathrm{~N} \cdot \mathrm{M} ， \quad 50 \mathrm{~N} \cdot \mathrm{M} ， \quad 75 \mathrm{~N} \cdot \mathrm{M} ， 100 \mathrm{~N} \cdot \mathrm{M} ， 125 \mathrm{~N} \cdot \mathrm{M} ， \quad 150 \mathrm{~N} \cdot \mathrm{M}$, $175 \mathrm{~N} \cdot \mathrm{M}$, and $200 \mathrm{~N} \cdot \mathrm{M}$ in order.

Together Figures 12 and 13 expectably show that the torsional vibration is reinforced while increasing torque fluctuation. Meanwhile an obvious increase in amplitude occurs at the second peak when fluctuation is increased from $175 \mathrm{~N} \cdot \mathrm{M}$ to $200 \mathrm{~N} \cdot \mathrm{M}$, which indicates that a limitation should be considered. The accurate value can be determined by a further study. In summary reducing torque fluctuation is a beneficial approach for vibration damping. Furthermore, it is noted that such a nonlinear phenomenon as natural frequency shift occurs while changing torque fluctuation. Taking the second-order torsional frequency as an example, the frequency value decreases with elevating fluctuation of input 


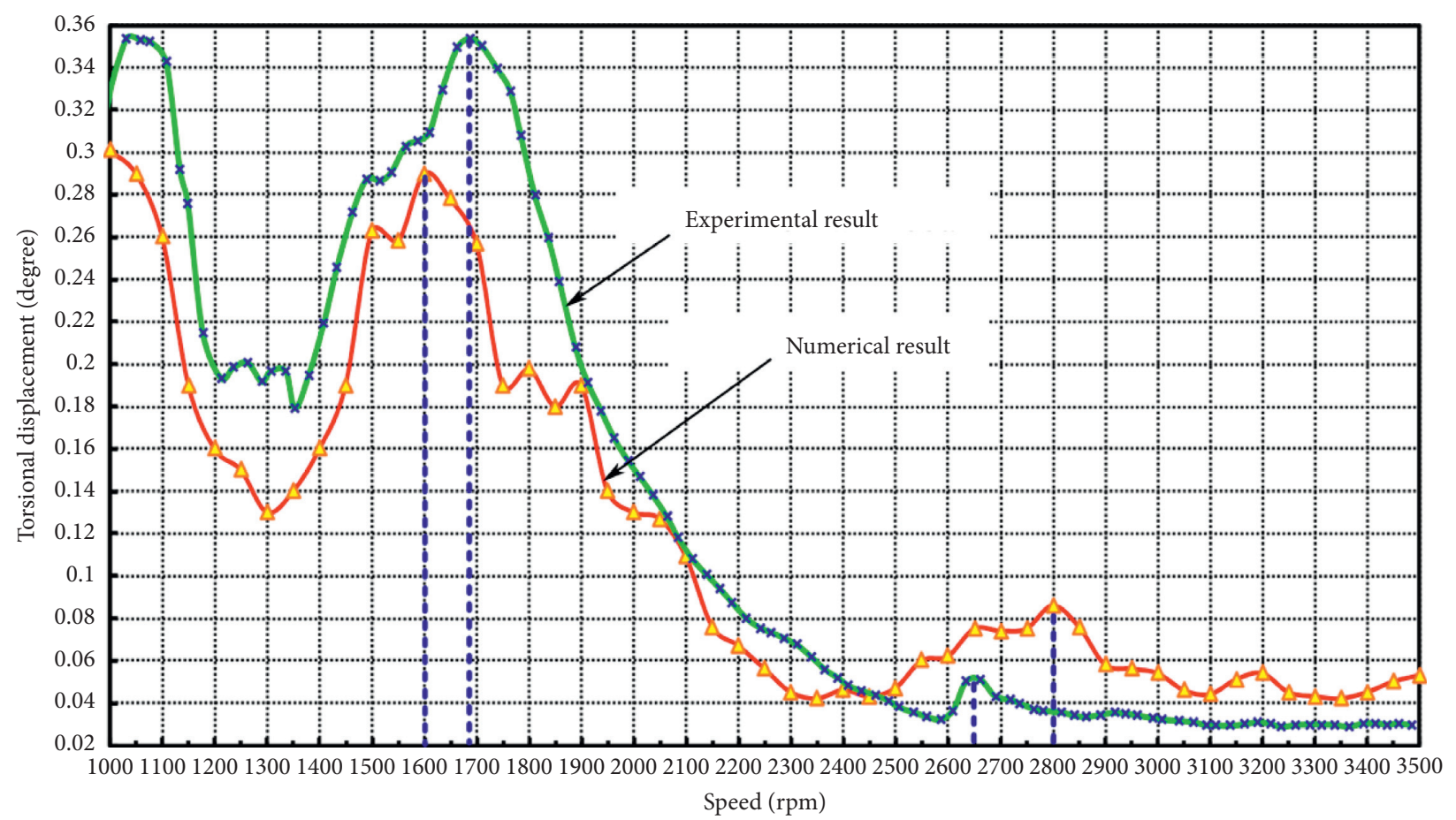

FIGURE 11: Comparison of numerical and experimental results for input end of rear axle.

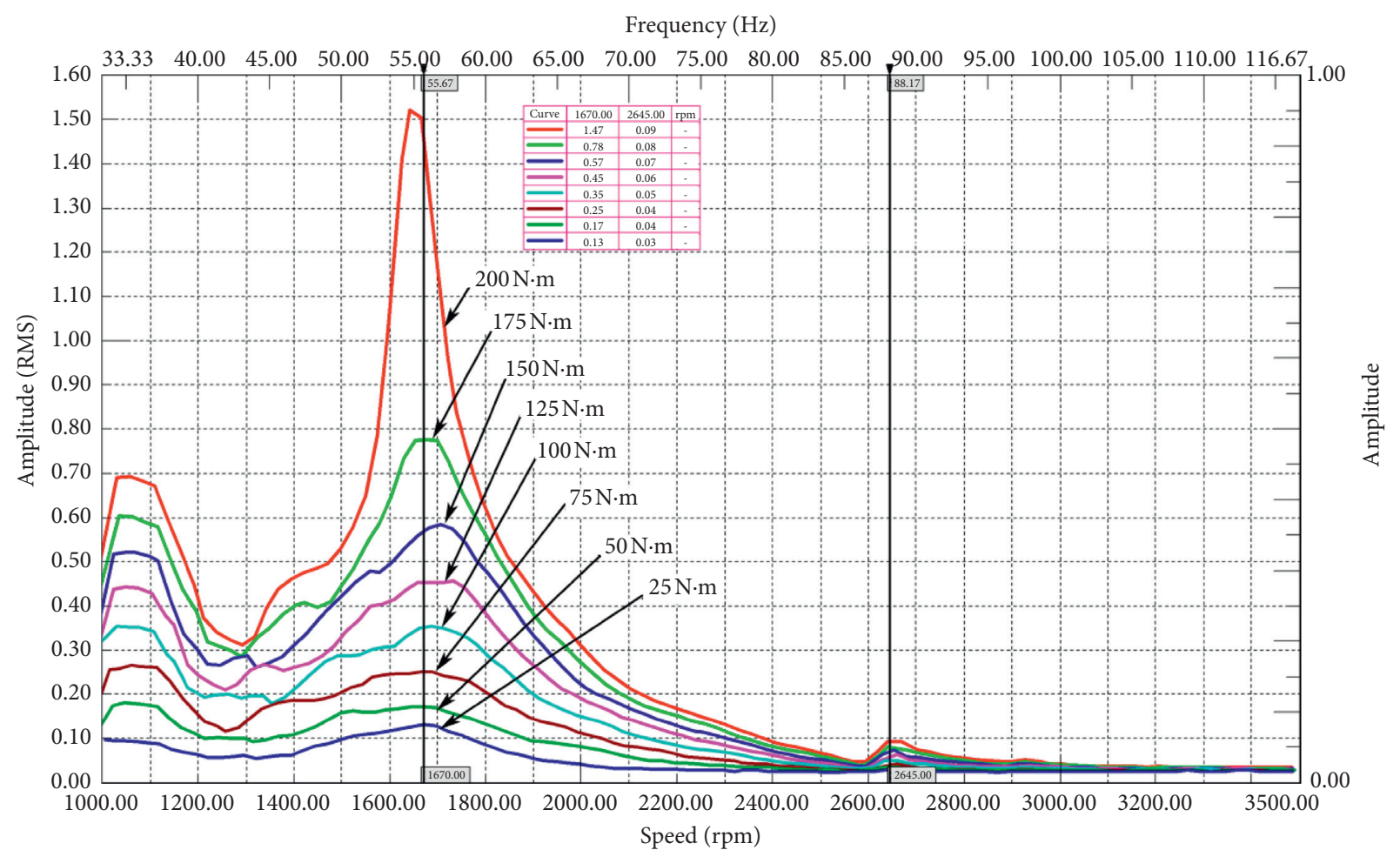

Figure 12: Amplitude-frequency responses of torsional vibration for input end of rear axle at different torque fluctuations. 


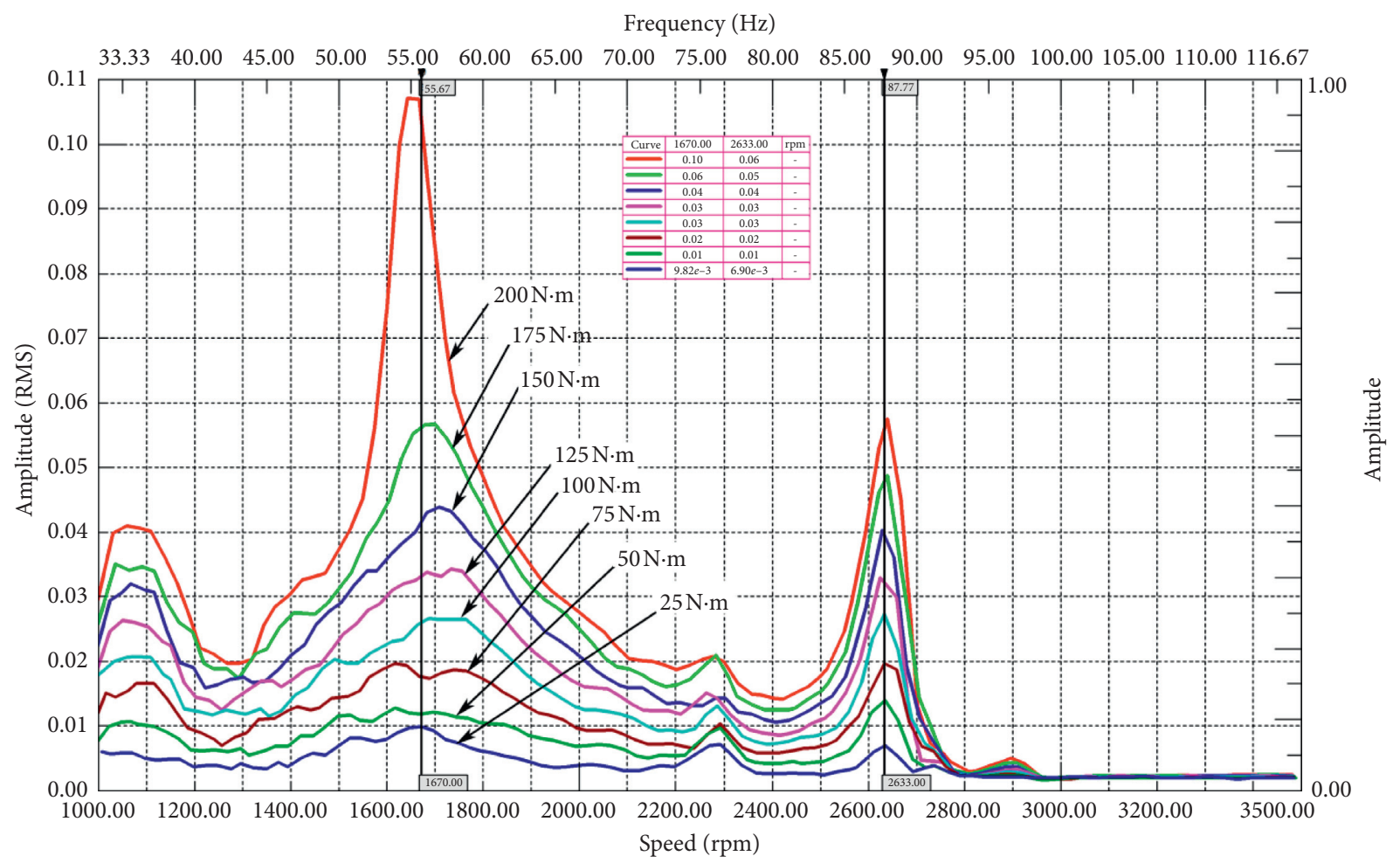

FIGURE 13: Amplitude-frequency responses of torsional vibration for output end of rear axle at different torque fluctuations.

torque, which shows that the torsional system has a stiffnesssoftening characteristic with respect to torque fluctuation. This result can be accounted for a number of nonlinearities, such as friction, clearance, and sliding, and the existence of which sophisticates system nonlinear characteristics.

\section{Conclusion}

In the present paper, a lumped-parameter dynamic model with 29 degree-of-freedom is proposed considering the transverse, torsional, and rocking coupled vibration for a better understanding of the automotive powertrain system dynamics and equations of motion are derived. The numerical result shows that gear mesh excitations have little effects on torsional response for such components located before the mesh point as transmission, transmission shaft, and pinion but significantly reduce the torsional responses for ones behind the mesh point. The amplitude-frequency characteristics of torsional vibration graphically indicate that torsional behaviors of automotive powertrain only affect the vibration characteristics of complete vehicle under lowspeed condition, and predict the first three-order nature torsional frequencies of the whole system. An experimental examination is performed and validates the feasibility of the considered model. The torsional vibration is reinforced while increasing torque fluctuation. In addition, a stiffness softening characteristic is observed for torsional vibration experimentally. In order to reach a better understanding in amplitude-frequency response at low- and middle-inputspeed condition, a procedure to analyze mode shapes of automotive powertrain will be conducted in future works.

\section{Data Availability}

The data used to support the findings of this study are included within the article.

\section{Conflicts of Interest}

The authors declare that they have no conflicts of interest.

\section{Acknowledgments}

This work was supported and funded by the Application Technology Research and Development Plan of Liuzhou City (grant no. 2017AA10102) and the Key Projects of Universities in Inner Mongolia Autonomous Region (grant no. NJZZ16369). The authors of this paper express their deep gratitude for the financial support of the research project.

\section{References}

[1] F. Vesali, M. A. Rezvani, and M. Kashfi, "Dynamics of universal joints, its failures and some propositions for practically improving its performance and life expectancy," Journal of Mechanical Science and Technology, vol. 26, no. 8, pp. 24392449, 2012.

[2] J.-W. Lu, G.-C. Wang, H. Chen, A. F. Vakakis, and L. A. Bergman, "Dynamic analysis of cross shaft type universal joint with clearance," Journal of Mechanical Science and Technology, vol. 27, no. 11, pp. 3201-3205, 2013.

[3] G. Wu, W. Shi, and Z. Chen, "The effect of multi-universal coupling phase on torsional vibration of drive shaft and vibration of vehicle," in Proceedings of the SAE 2013 World Congress \& Exhibition, Detroit, MI, USA, April 2013. 
[4] B. A. Porter, "Theoretical analysis of the torsional oscillation of a system incorporating a Hooke's joint," Journal of Mechanical Engineering Science, vol. 3, no. 4, pp. 324-329, 1961.

[5] S. F. Asokanthan and X.-H. Wang, "Characterization of torsional instabilities in a Hooke's joint driven system via maximal Lyapunov exponents," Journal of Sound and Vibration, vol. 194, no. 1, pp. 83-91, 1996.

[6] A. Farshidianfar, M. Ebrahimi, and H. Bartlett, "Hybrid modelling and simulation of the torsional vibration of vehicle driveline systems," Proceedings of the Institution of $\mathrm{Me}$ chanical Engineers, Part D: Journal of Automobile Engineering, vol. 215, no. 2, pp. 217-229, 2001.

[7] E. O. A. Abd Elmaksoud, E. M. Rabeih, N. A. Abdel-halim, and S. M. El Demerdash, "Investigation of self excited torsional vibrations of different configurations of automatic transmission systems during engagement," Engineering, vol. 3, no. 12, pp. 1171-1181, 2011.

[8] T. B. Juang, M. Cheng, and L. Na, "Experimental and finite element analyses of a sliding-tube-type driveshaft-induced vehicle vibration," Proceedings of the Institution of Mechanical Engineers, Part K: Journal of Multi-Body Dynamics, vol. 221, no. 3, pp. 375-385, 2007.

[9] L. F. Coutinho and A. Tamagna, "Flexural vibration analysis of constant velocity half-shafts," in Proceedings of the International Congress \& Exposition, Chicago, IL, ISA, 1996.

[10] Y. T. Kang, Y. H. Shen, W. Zhang, and J. Yang, "Stability region of floating intermediate support in a shaft system with multiple universal joints," Journal of Mechanical Science and Technology, vol. 28, no. 6, pp. 2733-2742, 2014.

[11] J. L. Xu, T. Yan, B. Peng, and B. Wei, "Effects of the transmission shaft on the main reducer vibration based on ADAMS and experimental demonstration," Australian Journal of Mechanical Engineering, vol. 15, no. 1, pp. 2-10, 2015.

[12] C. X. Zhang, H. B. Li, and D. Q. Jin, "Simulation on dynamics of transmission shaft-rear driving axle of minibus with ADAMS," Applied Mechanics and Materials, vol. 651-653, pp. 862-865, 2014.

[13] J. L. Xu, X. Y. Su, and P. Bo, "Numerical analysis and demonstration: transmission shaft influence on meshing vibration in driving and driven gears," Shock and Vibration, vol. 2015, Article ID 365084, 10 pages, 2015.

[14] J. L. Xu, W. Lei, and W. X. Luo, "Influence of bearing stiffness on the nonlinear dynamics of a shaft-final drive system," Shock and Vibration, vol. 2016, Article ID 3524609, 14 pages, 2016.

[15] A. Kahraman and R. Singh, "Non-linear dynamics of a spur gear pair," Journal of Sound and Vibration, vol. 142, no. 1, pp. 49-75, 1990.

[16] A. Kahraman and R. Singh, "Interactions between timevarying mesh stiffness and clearance non-linearities in a geared system," Journal of Sound and Vibration, vol. 146, no. 1, pp. 135-156, 1991.

[17] A. Kahraman, "Effect of axial vibrations on the dynamics of a helical gear pair," Journal of Vibration and Acoustics, vol. 115, no. 1, pp. 33-39, 1993.

[18] Y. Cai and T. Hayashi, "The linear approximated equation of vibration of a pair of spur gears (theory and experiment)," Journal of Mechanical Design, vol. 116, no. 2, pp. 558-564, 1994.

[19] P. Velex and M. Maatar, "A mathematical model for analyzing the influence of shape deviations and mounting errors on gear dynamic behaviour," Journal of Sound and Vibration, vol. 191, no. 5, pp. 629-660, 1996.
[20] P. Velex and V. Cahouet, "Experimental and numerical investigations on the influence of tooth friction in spur and helical gear dynamics," Journal of Mechanical Design, vol. 122, no. 4, pp. 515-522, 2000.

[21] P. Velex and P. Sainsot, "An analytical study of tooth friction excitations in errorless spur and helical gears," Mechanism and Machine Theory, vol. 37, no. 7, pp. 641-658, 2002.

[22] T. C. Lim and Y. Cheng, "A theoretical study of the effect of pinion offset on the dynamics of hypoid geared rotor system," Journal of Mechanical Design, vol. 121, no. 4, pp. 594-601, 1999.

[23] Y. Cheng and T. C. Lim, "Vibration analysis of hypoid transmissions applying an exact geometry-based gear mesh theory," Journal of Sound and Vibration, vol. 240, no. 3, pp. 519-543, 2001.

[24] Y. Cheng and T. C. Lim, "Dynamics of hypoid gear transmission with nonlinear time-varying mesh characteristics," Journal of Mechanical Design, vol. 125, no. 2, pp. 373-382, 2003.

[25] J. Wang, T. C. Lim, and M. Li, "Dynamics of a hypoid gear pair considering the effects of time-varying mesh parameters and backlash nonlinearity," Journal of Sound and Vibration, vol. 308, no. 2017, pp. 302-329, 2007.

[26] J. Wang and T. C. Lim, "Effect of tooth mesh stiffness asymmetric nonlinearity for drive and coast sides on hypoid gear dynamics," Journal of Sound and Vibration, vol. 319, no. 3-5, pp. 885-903, 2009.

[27] W. M. Li and H. T. Wang, "Rigidity calculation of axial position preload bearings," Journal of Hebei University of Technology, vol. 30, no. 2, pp. 15-19, 2001.

[28] A. Farshidianfar and A. Saghafi, "Global bifurcation and chaos analysis in nonlinear vibration of spur gear systems," Nonlinear Dynamics, vol. 75, no. 4, pp. 783-806, 2014.

[29] X. Liu, Z. Wu, J. Lu, and J. Xu, "Investigation of the effect of rotation speed on vibration responses of transmission system," Matec Web of Conferences, vol. 256, no. 3, Article ID 02019, 2019. 